\title{
Prevalence of gastrointestinal parasites in free-range yaks (Bos grunniens) in Gansu Province, Northwest China
}

\author{
Si-Yuan Qin ${ }^{1,2}$, Ming-Yang Yin², Guang-Yao Song ${ }^{2}$, Qi-Dong Tan ${ }^{3}$, Jin-Lei Wang ${ }^{2}$ and Dong-Hui Zhou ${ }^{2,4^{*}}$
}

\begin{abstract}
Background: Little information about the prevalence of gastrointestinal parasites in yaks (Bos grunniens) in northwest China is available. Therefore, the objective of the study was to quantify faecal egg counts of gastrointestinal parasites (helminths and coccidia) in free-range yaks from Gannan Tibetan Autonomous Prefecture, Gansu Province, Northwest China.

Results: Parasites were detected in 290 of 733 (39.56\%) faecal samples. The results showed that Strongylidae, Trichuris spp. and Eimeria spp. were detected all year round, Strongyloides papillosus was detected in autumn and summer, and Nematodirus spp. was detected in both autumn and spring. In contrast, Fasciola spp. was only detected in spring. The prevalence rates of parasitic infections in different seasons were significantly different.

Conclusions: To our knowledge, this is the first investigation of gastrointestinal parasites in yaks (Bos grunniens) in Gansu, China. The results demonstrated a high prevalence of gastrointestinal parasitic infections, specifically GN infections, in yaks in GTAP and these infections can cause economic losses to the local cattle industry.
\end{abstract}

Keywords: Prevalence, Gastrointestinal parasite, Yak, China

\section{Background}

In ruminants, gastrointestinal parasites, especially nematodes, can cause parasitic gastroenteritis (PG), which may lead to economic losses for livestock farmers [1]. The clinical symptoms of PG include weight loss, diarrhoea, anaemia and oedema. Livestock harbouring a diversity of parasite species will suffer severe symptoms [2]. The yak is a long-haired bovid found throughout the Himalayan region of southern Central Asia and the Tibetan Plateau and as far north as Mongolia and Russia. Most yaks are domesticated and are recognized as a major source of income for people in Gannan Tibetan Autonomous Prefecture (GTAP). The milk and meat of white yaks are popular delicacies for local Tibetan people and other residents in Gansu Province. However, it is very common that gastrointestinal parasitic infections cause a decline in milk production, weight loss

\footnotetext{
*Correspondence: donghui822002@163.com

${ }^{4}$ Key Laboratory of Fujian-Taiwan Animal Pathogen Biology, College of Animal Sciences, Fujian Agriculture and Forestry University, Fuzhou, Fujian Province 350002, People's Republic of China

Full list of author information is available at the end of the article
}

and even death in yaks. Although some studies have reported the incidence of gastrointestinal helminthic infections in yaks in India [3-5] and in some provinces in China [6-10], there is little information about gastrointestinal parasitic infection in yaks in Gansu, China. To the best of our knowledge, this is the first study to estimate the prevalence of gastrointestinal parasites in yaks in the plateau areas of GTAP, Gansu, China.

\section{Results}

The mean prevalence of gastrointestinal parasites in yaks is shown in Table 1. The Strongylidae and Trichuris spp. eggs were detected all year round. However, Strongyloides papillosus eggs were detected in only autumn and summer, Nematodirus spp. were detected in only autumn and spring, and Fasciola eggs were detected in only spring. The prevalence of Eimeria spp. in the different seasons ranged from 11.92 to $22.12 \%$. A total of $39.56 \%$ (290) of the 733 faecal samples were positive for gastrointestinal parasite infection (Table 2). The prevalence of gastrointestinal parasites in yaks in the winter pastures $(43.00 \%)$ was significantly higher than that in yaks in the summer

(c) The Author(s). 2019 Open Access This article is distributed under the terms of the Creative Commons Attribution 4.0 International License (http://creativecommons.org/licenses/by/4.0/), which permits unrestricted use, distribution, and 
Table 1 Prevalence of nematodes, trematode and protozoan in yaks in Gansu, China

\begin{tabular}{|c|c|c|c|c|c|c|c|c|}
\hline \multirow[t]{2}{*}{ Parasites } & \multicolumn{2}{|l|}{ Autumn } & \multicolumn{2}{|l|}{ Winter } & \multicolumn{2}{|l|}{ Spring } & \multicolumn{2}{|l|}{ Summer } \\
\hline & $\begin{array}{l}\text { No.positive/ } \\
\text { Prevalence (\%) }\end{array}$ & $95 \% \mathrm{Cl}^{\mathrm{a}}$ & $\begin{array}{l}\text { No.positive/ } \\
\text { Prevalence (\%) }\end{array}$ & $95 \% \mathrm{Cl}$ & $\begin{array}{l}\text { No.positive/ } \\
\text { Prevalence (\%) }\end{array}$ & $95 \% \mathrm{Cl}$ & $\begin{array}{l}\text { No.positive/ } \\
\text { Prevalence (\%) }\end{array}$ & $95 \% \mathrm{Cl}$ \\
\hline \multicolumn{9}{|l|}{ Nematodes } \\
\hline Strongylidae & $89.00 / 28.53$ & $23.52-33.54$ & $14.00 / 13.75$ & $6.27-19.22$ & $80.00 / 47.93$ & $62.06-76.04$ & $8.00 / 5.30$ & $1.73-8.87$ \\
\hline Strongyloides papillosus & 19.00/6.09 & $3.44-8.70$ & $N D^{b}$ & - & ND & - & $1.00 / 0.66$ & $0.00-1.96$ \\
\hline Trichuris spp. & $5.00 / 1.60$ & $0.21-3.00$ & $1.00 / 0.98$ & $0.00-2.89$ & 20.00/11.91 & $7.01-16.80$ & $3.00 / 1.99$ & $0.00-4.21$ \\
\hline Nematodirus spp. & 69.00/22.12 & $17.51-26.72$ & ND & - & $4.00 / 2.38$ & $0.08-4.69$ & ND & - \\
\hline \multicolumn{9}{|l|}{ Protozoan } \\
\hline Eimeria spp. & $69.00 / 22.12$ & $17.51-26.72$ & $15.00 / 14.71$ & $7.83-21.58$ & 23.00/13.69 & 8.49-18.89 & 18.00/11.92 & $6.75-17.09$ \\
\hline \multicolumn{9}{|l|}{ Trematode } \\
\hline Fasciola spp. & ND & - & ND & - & $11 / 6.55$ & $2.81-10.29$ & ND & - \\
\hline
\end{tabular}

a Confidence intervals

${ }^{\mathrm{b}}$ Not detected

pastures $(35.11 \%) \quad\left(\chi^{2}=4.69, P=0.03\right) \quad($ Table 2). The prevalence of gastrointestinal parasites in yaks in the different seasons was $52.24 \%$ (autumn), $14.71 \%$ (winter), $58.93 \%$ (spring), and $8.61 \%$ (summer), and the prevalence rates were significantly different between the different seasons $\left(X^{2}=134.197, P<0.01\right)$.

The mean EPG of Strongylidae and Nematodirus spp. and the mean OPG of Eimeria spp. in the different seasons are shown in Table 3. Interestingly, there were no Strongylidae and Nematodirus spp. collected in winter and summer. The mean EPG of Strongylidae in autumn and spring were 27.0 and 70.7, respectively. Furthermore, the mean EPG of Nematodirus spp. was lower in autumn (47.2) than in spring (50.0), and the mean OPG of Eimeria spp. in winter (26.7) and summer (66.7) were higher than those in autumn (15.9) and spring (13.0).

\section{Discussion}

The total prevalence of gastrointestinal parasite infection in yaks was $39.56 \%$, which was lower than that in India (91.1\%) [5] but higher than the multiple parasitic infection rate $(7.47 \%)$ in yaks in North Sikkim, India [4]. The difference in the parasite prevalence may result from differences in immune capacities, feeding conditions, ecological conditions, temperature conditions, sampling seasons and animal welfare conditions.

The prevalence rates of gastrointestinal parasite infections in autumn, winter, spring and summer were 52.24, $14.71,58.92$ and $8.61 \%$, respectively. The results of the chi-square test showed that the differences in the prevalence of gastrointestinal helminthic infections in the different seasons were significant $(P<0.05)$. Relevant research indicated that the prevalence of parasitic infection in spring was the highest, which was in accordance with the results of this study [3]. The reason for the different prevalence rates in the different seasons is as follows. The inhibitory larvae begin to grow when the weather becomes warm in early spring. After several days of growth, there is a peak period of ovulation. In summer, the number of eggs decrease because the ovulation of adult helminths is reduced. However, there are large numbers of L3 larvae in the grassland, and they may infect the yaks. For example, Ostertagia ostertagi can develop into L3 larvae in approximately 5-6 days at $25^{\circ} \mathrm{C}$ [11]. The larvae can exit the faeces and protect themselves. The surviving larvae contaminate the grass and soil [12]. Then, there is a new peak period of ovulation in autumn as the L3 larvae become adults. The worm die of old age during the winter and the egg output declines accordingly [13]. In addition, the winter

Table 2 Prevalence of gastrointestinal parasites infection in different pastures

\begin{tabular}{lllll}
\hline Pastures & No. tested & No. positive & Prevalence (\%) & $95 \% \mathrm{Cl}^{\mathrm{a}}$ \\
\hline Winter pastures $^{\mathrm{b}}$ & 414 & 178 & 43.00 & $38.23-47.76$ \\
Summer pastures $^{c}$ & 319 & 112 & 35.11 & $29.87-40.35$ \\
Total & 733 & 290 & 39.56 & $36.02-43.10$ \\
\hline
\end{tabular}

a Confidence intervals

${ }^{b}$ Autumn and winter

c Spring and summer

$X^{2}=4.69, P=0.03$ 
Table 3 Means of epg of gastrointestinal parasites in different seasons

\begin{tabular}{|c|c|c|c|c|c|c|c|c|c|c|c|c|}
\hline \multirow[t]{2}{*}{ Parasites } & \multicolumn{3}{|c|}{ Autumn } & \multicolumn{3}{|l|}{ Winter } & \multicolumn{3}{|l|}{ Spring } & \multicolumn{3}{|c|}{ Summer } \\
\hline & Mean $^{a}$ & $\mathrm{SE}^{\mathrm{b}}$ & Min.-Max. ${ }^{c}$ & Mean & SE & Min.-Max. & Mean & SE & Min.-Max. & Mean & SE & Min.-Max \\
\hline Strongylidae & 31.4 & \pm 8.3 & $0.0-400.0$ & $N D^{d}$ & - & - & 97.6 & \pm 16.6 & $0.0-700.0$ & 25.0 & \pm 25.0 & $0.0-200.0$ \\
\hline Nematodirus spp. & 47.2 & \pm 10.5 & $0.0-400.0$ & ND & - & - & 50.0 & \pm 28.9 & $0.0-100.0$ & ND & - & - \\
\hline Eimeria spp. & 15.9 & \pm 7.6 & $0.0-400.0$ & 26.7 & \pm 15.3 & $0.0-200.0$ & 13.0 & \pm 7.2 & $0.0-100.0$ & 44.4 & \pm 27.1 & $0.0-400.0$ \\
\hline
\end{tabular}

${ }^{a}$ Mean epg

b Standard error

c Min. minimum ranges, Max. maximum ranges

${ }^{d}$ Not detected

temperature in GTAP decreases significantly, which has a negative effect on the growth of gastrointestinal parasites.

The yaks are grazed on different pastures in winter and summer in GTAP. The statistical analysis indicated that the difference in the gastrointestinal helminthic infection rates between animals in the winter pastures and animals in the summer pastures was significant $(P<$ $0.05)$, suggesting that the risk for gastrointestinal helminthic infection was higher in winter pastures than in summer pastures.

The EPG of gastrointestinal nematodes ranged from 0 to 700. The EPG of both Strongylidae and Nematodirus spp. in winter were 0, and the EPG of Nematodirus spp. in summer was 0 , suggesting that the intensity of infection was not relatively high. Eimeria spp. was detected in each season, and the total prevalence was $17.05 \%$ (not shown), which was lower than that in Qinghai-Tibet and in Kenya $[14,15]$. This is the first report on the dynamics of Eimeria spp. prevalence in yaks in China; however, further studies are needed to explain the difference above.

\section{Conclusions}

This study investigated gastrointestinal parasitic infections in free-range yaks in Gansu, China, for the first time. The results demonstrated a high prevalence of gastrointestinal parasitic infections, specifically GN infections, in yaks in GTAP and these infections can cause economic losses for the local cattle industry in this area. The results of this study can help yak herders and veterinary professionals take action to prevent and control parasitic infections based on the prevalence of parasitic infections in different seasons and areas and the species of parasites to reduce parasitic infection burdens and increase productivity in the yaks.

\section{Methods}

\section{Study area}

This study was carried out from October 2013 to July 2014 in GTAP, which is located in the south of Gansu Province, China. The latitude and longitude of the high plateau area are $33^{\circ} 06^{\prime}-34^{\circ} 33^{\prime} \mathrm{N}$ and $100^{\circ} 46^{\prime}-102^{\circ} 29^{\prime} \mathrm{E}$, respectively, while the altitude is between 3300 and $4806 \mathrm{~m}$. The average annual temperature is $1.1^{\circ} \mathrm{C}$.

\section{Faecal samples}

A total of 733 samples were collected during the four seasons of the year, and the number of samples collected in each season was as follows: autumn (312), winter (102), spring (168), and summer (151). Faecal samples were collected randomly from winter pastures (from October to March) and summer pastures (from April to September), including 8 farms according to the protocol of a previous study with some modifications [16]. Briefly, approximately $50 \mathrm{~g}$ fresh samples were collected from the floor immediately after animal defecation; the samples were put into disposable plastic gloves marked with locations, serial numbers and collection dates. Samples were placed in ice boxes and transported to the laboratory, then stored in refrigerators at $4{ }^{\circ} \mathrm{C}$ and processed as soon as possible.

\section{Coprological examination Centrifugation}

Two grams of a fresh faecal sample was added to water 5 times its volume, and the faecal and water were mixed equally. Each dilution was poured through a wire mesh screen with an aperture of $350 \mu \mathrm{m}$, and the liquid was collected. The liquid was centrifuged for $2 \mathrm{~min}$ at 3000 $\mathrm{rpm}$, and the supernatant was poured off and discarded. Precipitates were used for smearing to detect trematode and cestode eggs. Based on our previous experiments, the result was not good using raw fecal samples by sugar flotation. So we used precipitated fecal samples by taking the extra step of the water wash in the sugar floatation method.

\section{Sugar floatation method}

The precipitates above were resuspended with $30 \mathrm{~mL}$ of Sheather's sucrose solution and centrifuged for $5 \mathrm{~min}$ at $3000 \mathrm{rpm}$ according to a previous report [17]. Iron loops were used to create a smear to detect nematode eggs and coccidial oocysts. 


\section{Faecal egg counts}

The modified McMaster technique was used to count nematode eggs and coccidial oocysts in fresh faecal samples. An animal was recognized as severely infectied when faecal egg counts exceeded 500 eggs per gram of faeces (EPG) [18].

\section{Statistical analysis}

The mean prevalence and confidence intervals were determined for gastrointestinal parasites, and the mean EPG and oocyst per gram of faeces (OPG), minimum and maximum ranges and standard errors were determined for gastrointestinal nematodes (GNs) and Eimeria spp. using the analytic software (PASW ${ }^{\circ}$ ) Statistics 18 . The chisquare test was performed for GN collected in different seasons and from different pastures using the general linear model procedure with the statistical software.

\section{Abbreviations}

EPG: Eggs per gram; GN: Gastrointestinal nematode; GTAP: Gannan Tibetan Autonomous Prefecture; OPG: Oocyst per gram; PG: Parasitic gastroenteritis

\section{Acknowledgements}

Not applicable.

\section{Authors' contributions}

SYQ and DHZ conceived and designed the study and critically revised the manuscript. MYY, GYS, QDT and JLW collected the samples, performed the experiments, analysed the data and drafted the manuscript. All authors read and approved the final manuscript.

\section{Funding}

The work was funded by the "Special Fund for Agro-scientific Research in the Public Interest" (Grant No. 201303037), the "Special Fund for Forestry Scientific Research in the Public Interest" (Grant No. 201504310) and Self-listed Scientific Research Projects from General Station of Forest and Grassland pest Management, National Forestry and Grassland Administration. All funding bodies had no role in the design of the study and collection, analysis, and interpretation of data and in writing the manuscript.

\section{Availability of data and materials}

The datasets used and analyzed during the study are available from the corresponding author on reasonable request.

\section{Ethics approval}

This study was approved by the Animal Ethics Committee of Lanzhou Veterinary Research Institute, Chinese Academy of Agricultural Sciences (Approval No. LVRIAEC2013-010). The samples were collected and handled in accordance with the good animal practices required by the Animal Ethics Procedures and Guidelines of the People's Republic of China. The animals in our study were from several farms in Gansu Province. For the field trials, informed verbal consent was obtained from the farmers. Verbal consent was chosen since a large proportion of the local rural population are illiterates. This proceeding was approved by the Ethics Committee.

\section{Consent for publication}

Not applicable.

\section{Competing interests}

The authors declare that they have no competing interests. of Agricultural Sciences, Lanzhou, Gansu Province, People's Republic of China. ${ }^{3}$ Animal Quarantine Station of Beijing Entry-Exit Inspection and Quarantine Bureau, Beijing 101312, People's Republic of China. ${ }^{4}$ Key Laboratory of Fujian-Taiwan Animal Pathogen Biology, College of Animal Sciences, Fujian Agriculture and Forestry University, Fuzhou, Fujian Province 350002, People's Republic of China.

Received: 14 May 2019 Accepted: 20 September 2019

Published online: 15 November 2019

\section{References}

1. Newton SE. Progress on vaccination against Haemonchus contortus. Int J Parasitol. 1995;25:1281-9.

2. Wimmer B, Craig BH, Pilkington JG, Pemberton JM. Non-invasive assessment of parasitic nematode species diversity in wild Soay sheep using molecular markers. Int J Parasitol. 2004;34:625-31.

3. Bam J, Deori S, Paul V, Bhattacharya D, Bera AK, Bora L, et al. Seasonal prevalence of parasitic infection of yaks in Arunachal Pradesh, India. Asian Pac J Trop Dis. 2012;2:264-7.

4. Bandyopadhyay S, Pal P, Bhattacharya D, Bera AK, Pan D, Rahman H. A report on the prevalence of gastrointestinal parasites in yaks (Bos poephagus) in the cold desert area of North Sikkim, India. Trop Anim Health Prod. 2010;42:119-21.

5. RangaRao GS, Sharma RL. Hemaprasanth, parasitic infections of Indian yak Bos (poephagus) grunniens-an overview. Vet Parasitol. 1994;53:75-82.

6. Du XJ, Wang Z, Zhang YT, Liu QS and Bayinchahan Prevalence of Babesia bigemina and helminth in yak in Xinjiang. Anim Husbandry Vet Med 2014;1: 92-94 (In Chinese).

7. Hu GW, Cai JS, Ma RL, Zhao QB, Ma ZQ, Li LF, et al. Dynamic prevalence of parasites in yak in South Guizhou. China J Vet Med. 2013;7:45-7 (In Chinese).

8. Jiang XL. Study of parasites in yak in Sichuan. China Yak. 1987;2:30-8 (In Chinese).

9. Liu WD, Peng M, Jiang YS, Li W, Fu LC. Prevalence of parasites in yak in Qinghai and identification of parasites in yak in China. China Vet Sci. 1989;6: 18-20 (In Chinese).

10. Wu J, Jiang $X L$, Zhou DY. The report of parasitic infection in yaks. Chin J Vet Med. 1964;9:1-2 (In Chinese).

11. Ciordia H, Bizzell WE. The effects of various constant temperatures on the development of free living-stages of some nematode parasites of cattle. J Parasitol. 1963;49:60-3.

12. Stromberg BE. Environmental factors influencing transmission. Vet Parasitol. 1997:72:247-64.

13. Roberts JL, Swan RA. Quantitative studies of ovine haemonchosis. I. Relationship between faecal egg counts and total worm counts. Vet Parasitol. 1981;8:165-71.

14. Munyua WK, Ngotho JW. Prevalence of Eimeria species in cattle in Kenya. Vet Parasitol. 1990;35:163-8.

15. Dong H, Li C, Zhao Q, Li J, Han H, Jiang L, et al. Prevalence of Eimeria infection in yaks on the Qinghai-Tibet plateau of China. J Parasitol. 2012;98: 958-62.

16. Mi R, Wang X, Li C, Huang Y, Zhou P, Li Z, et al. Prevalence and genetic characterization of Cryptosporidium in yaks in Qinghai Province of China. PLoS One. 2013;8:e74985.

17. Cringoli G, Rinaldi L, Veneziano V, Capelli G, Scala A. The influence of flotation solution, sample dilution and the choice of McMaster slide area (volume) on the reliability of the McMaster technique in estimating the faecal egg counts of gastrointestinal strongyles and Dicrocoelium dendriticum in sheep. Vet Parasitol. 2004;123:121-31.

18. Keyyu JD, Kyvsgaard NC, Monrad J, Kassukum AA. Epidemiology of gastrointestinal nematodes in cattle on traditional, small-scale and largescale dairy farms in Iringa District. Tanzania Vet Parasitol. 2005;127:285-94.

\section{Publisher's Note}

Springer Nature remains neutral with regard to jurisdictional claims in published maps and institutional affiliations.

\section{Author details}

${ }^{1}$ General Station for the Surveillance of Wildlife-borne Infectious Diseases, State Forestry and Grassland Administration, Shenyang, Liaoning Province 110034, People's Republic of China. ${ }^{2}$ State Key Laboratory of Veterinary Etiological Biology, Lanzhou Veterinary Research Institute, Chinese Academy 